In der Rubrik „Literatur kompakt" werden die wichtigsten Originalarbeiten aus der internationalen Fachliteratur referiert.

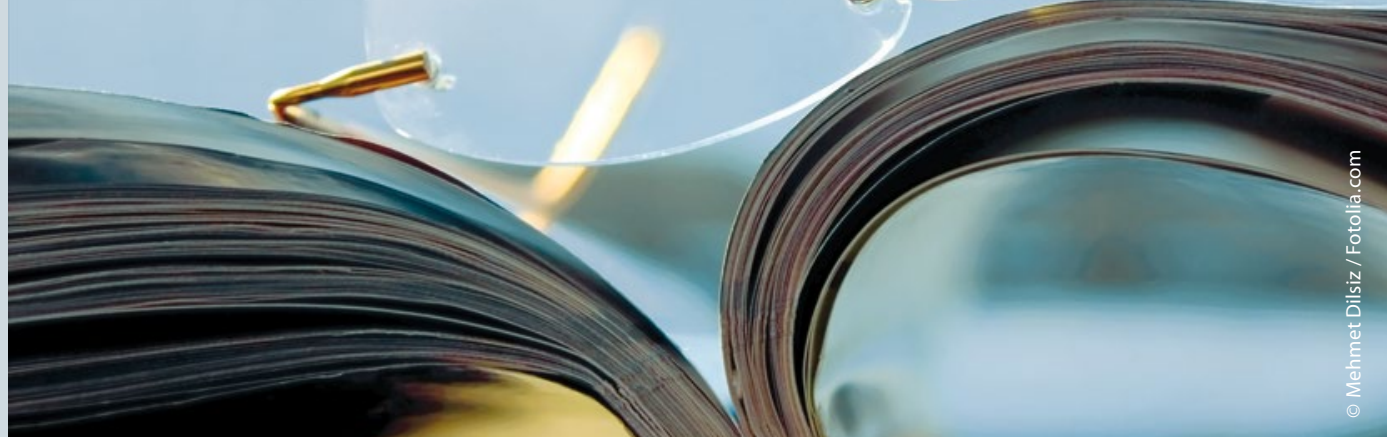

\section{Überraschendes Signal steuert männliche Fruchtbarkeit}

\begin{abstract}
Spermienzellen reifen bei ihrer Passage durch den Nebenhoden aus und erlangen erst dabei die Fähigkeit, Eizellen zu befruchten. Deutsche Forscher haben nun entdeckt, dass Signalmoleküle diesen Reifungsprozess koordinieren.
\end{abstract}

D er Reifungsprozess von Spermien wird durch Signalmoleküle der Wnt-Familie koordiniert, berichten Wissenschaftler vom Deutschen Krebsforschungszentrum (DKFZ) in Heidelberg und vom Institut für Molekulare Biologie in Mainz. Das überraschende daran: Der für die Embryonalentwicklung und für die Entstehung von Krankheiten extrem bedeutende Signalweg wirkt auf die Spermatozoen anders als bisher bekannt.

Wnt bindet an Rezeptoren auf der Zelloberfläche und übt seine klassischen Funktionen über eine äußerst komplexe Kaskade von Proteinwechselwirkungen im Zellinneren aus. Am Ende dieses intrazellulären Signalwegs werden im Zellkern bestimmte Gene abgelesen das bekannte Wnt-Signal fördert die Transkription. „Wir haben uns immer gefragt, ob Wnt auch Funktionen im Körper steuern kann, ohne dass Gene aktiviert und abgelesen werden", so Prof. Christof Niehrs vom DKFZ. Niehrs und seine Mitarbeiter hatten kürzlich erste Hinweise darauf gefunden, dass der Wnt-Signalweg unabhängig von seinem Einfluss auf die Transkription, Proteine vor dem Abbau schützt. Dadurch können Zellen an Größe zulegen und sich auf die Zellteilung vorbereiten. Allerdings, so schränkten die Forscher ein, ist eine transkriptions-unabhängige
Funktion von Wnt extrem schwierig zu beweisen: $\mathrm{Zu}$ stark und vielfältig ist der Einfluss des Signalmoleküls auf die Genaktivität. So entdeckten die Forscher Spermien als ideales Studienobjekt für diese Fragestellung: Spermien fehlen die biologischen Voraussetzungen für die Transkription, in den Samenzellen werden keinerlei Gene abgelesen. Sollte Wnt tatsächlich eine Wirkung auf die männlichen Geschlechtszellen haben, so müsste diese auf andere Weise zustande kommen.

Spermien reifen bei ihrer Passage durch den Nebenhoden, erst dort erlangen sie ihre Beweglichkeit und werden befruchtungsfähig. Einen der geheimnisvollen Faktoren hinter diesem Reifungsprozess konnten Stefan Koch und Sergio P. Acebron aus Nierhs Forschungsteam nun an Mäusen identifizieren. Von Zellen des Nebenhodens abgegebenes Wnt sorgt für die essenzielle Beweglichkeit und für entscheidende Änderungen der Proteineigenschaften in den Samenzellen. Dabei verläuft das Wnt-Signal im Inneren der Spermien über die üblichen, bekannten Schaltstationen - beeinflusst am Ende aber andere Zielmoleküle. Männliche Mäuse, denen ein neu entdeckter wichtiger Aktivator des klassischen Wnt-Signalwegs fehlt, sind steril, ihre Spermien missgebildet und unbeweglich.
Fazit: „Mit den Ergebnissen konnten wir wissenschaftlich zwei Fliegen mit einer Klappe schlagen", sagte Niehrs. „Erstens haben wir einwandfrei belegt, dass der klassische Wnt-Signalweg Körperfunktionen steuert, ohne dazu die Transkription anzukurbeln. Und wir kennen nun den entscheidenden Faktor, der das Reifungsprogramm der Spermien koordiniert." Koch schlussfolgerte aus den Untersuchungen: „Wnt hat offensichtlich einen erheblichen Einfluss auf die männliche Fruchtbarkeit. Wirkstoffe, die den Wnt-Signalweg blockieren oder aktivieren, werden teilweise bereits in klinischen Studien für andere Zulassungen geprüft. Sie könnten möglicherweise auch bei Fruchtbarkeitsstörungen oder aber bei der Verhütung wirksam sein“.

Wolfgang Geissel

Koch S, Acebron SP, Herbst J, Hatiboglu G, Niehrs C. Post-transcriptional Wnt signaling governs epididymal sperm maturation. CELL. 2015;163:1225-36

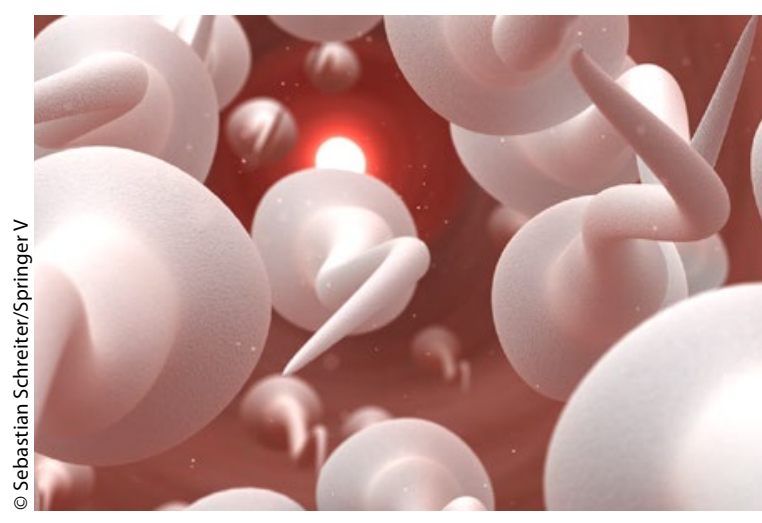

Spermienzellen reifen mithilfe des Signalmoleküls WnT. 